\title{
An Efficient Synthesis of Milnacipran Hydrochloride via Reductive Amination of Aldehyde
}

\author{
Neha Reddy Desireddy, ${ }^{1}$ Arava Glory, ${ }^{2}$ Krishna Reddy Bhimireddy, \\ Yadagiri Kurra, ${ }^{3}$ and Ram Reddy ${ }^{1}$ \\ ${ }^{1}$ Nifty Labs Pvt. Ltd., Hyderabad 500016, India \\ ${ }^{2}$ Sri Venkateswara University, Tirupathi 517502, India \\ ${ }^{3}$ Texas A\&M University, College Station, TX 77843, USA \\ Correspondence should be addressed to Ram Reddy; ram.2006r@gmail.com
}

Received 14 November 2016; Revised 31 January 2017; Accepted 27 February 2017; Published 20 March 2017

Academic Editor: Mohamed Afzal Pasha

Copyright (C) 2017 Neha Reddy Desireddy et al. This is an open access article distributed under the Creative Commons Attribution License, which permits unrestricted use, distribution, and reproduction in any medium, provided the original work is properly cited.

An efficient synthesis of milnacipran hydrochloride has been accomplished. The important application of this paper is the reductive amination of aldehyde to primary amine with water soluble reagents. This method provides a high yield of primary amine as the major product, reduces the number of steps, and discourages by-products.

\section{Introduction}

Milnacipran hydrochloride is an antidepressant inhibiting the recapture of serotonin-noradrenaline recommended in the treatment of depression. US Food and Drug Administration (FDA) approved milnacipran under the brand name of Savella ${ }^{\circledR}$ for the treatment of fibromyalgia $[1,2]$. Several research groups [3-6] show high interest to devise an efficient synthesis of milnacipran with high enantiomeric purity. Because it is hydrophilic molecule with low lipophilicity makes this molecule differ from other drugs. Due to features, milnacipran exhibits almost ideal pharmacokinetics in humans (see Scheme 1).

Interesting structural features combined with the important biological activity of milnacipran have attracted us to attempt its synthesis through the oxidation and reductive amination method.

The primary amines are important building blocks in pharmaceutical and agrochemical industries and also useful applications in organic chemistry. The primary amine of milnacipran acts as chromophore and based on hydrophilic makes this molecule differ from other drugs. The synthesis of primary amine is very challenging reaction to avoid the overalkylation when employed metal reductive amination.
Generally protecting groups have been employed when preparing primary amines via metal hydride reductive amination to control the overalkylation [3-9]. Protecting groups have an important role in organic synthesis [10-13]. On the other hand, the incorporation of protecting group into synthetic route increases the total number of steps, decreases yield, and decreases atom economy [14]. Protecting groups also add functional groups and structural complexity to a molecule, which can have detrimental effects on orthogonality and reactivity. In metal hydride reductive aminations, the use of protecting groups is crucial to prevent overalkylation $[15,16]$ (Scheme 2). In this reaction aldehyde (I) reacts with ammonia to form an imine (II) that is subsequently reduced with sodium cyanoborohydride $\left(\mathrm{NaCNBH}_{3}\right)$ [17] to give the desired amine product (III). Without a protecting group, multiple alkylation events typically occur, resulting in the formation of the undesired secondary (V) or tertiary (VI) amine products. To avoid protecting groups as well as overalkylation, we attempted using excess of ammonia or adjusting $\mathrm{pH}$ through reductive amination.

Several strategies have already been developed for the synthesis of milnacipran in their racemic and pure form $[3-6,18,19]$. However, all these routes were involving the 


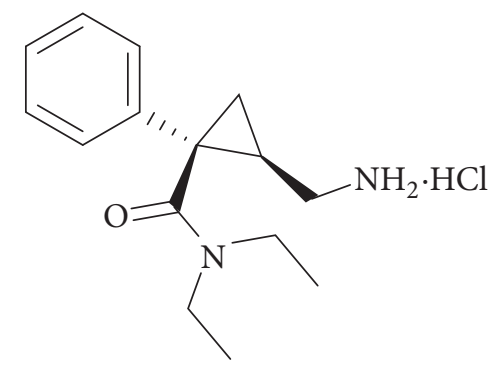

SCHEME 1

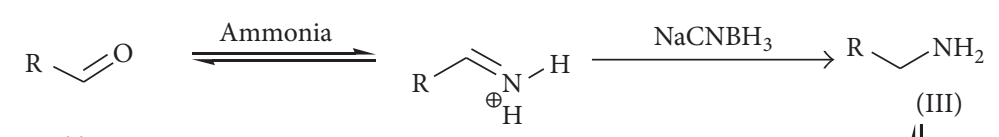

(I)

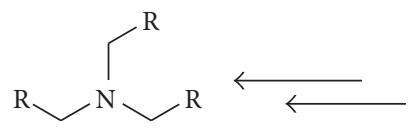

(VI)
(II)<smiles>[R]CNC[R]</smiles>

(V)

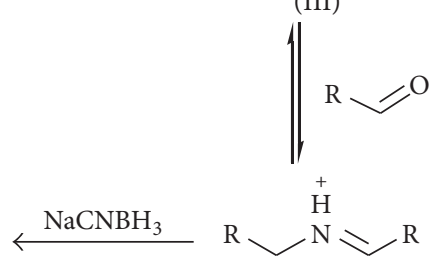

(IV)

SCHEme 2: Reductive amination of aldehydes.<smiles>CCN(CC)C(=O)[C@]1(c2ccccc2)C[C@H]1CO</smiles><smiles>CCN(CC)C(=O)C1(c2ccccc2)CC1CN</smiles><smiles>CCN(CC)C(=O)C1(c2ccccc2)CC1CN</smiles>

SCHEME 3

synthesis of the primary amine group through protection and deprotection. The protection and deprotection of potassium phthalimide significantly reduce the atom economy, yield, and increase the impurities as well as number of steps [20, 21]. Some synthetic protocols required special handling and more precautions, such as lithium amide and hydrogenation. Shuto et al. reported the synthesis of milnacipran with expensive and more cautious reagents such as sodium azide and appel reaction conditions followed by hydrogenation (Scheme 3 ) $[22,23]$. By the comparison our synthetic route is more reliable, more atom economy, and cost effective route with less by-products.

To overcome all these issues, we report a practical synthesis of milnacipran hydrochloride using a combination of oxidation and reductive amination.

\section{Results and Discussion}

Our synthetic strategy is outlined in Scheme 4. The target primary amine compound $\mathbf{1}$ could be prepared from commercially available compound [24] (1S*, 5R*)-1-phenyl-3oxabicyclo[3.1.0] hexane-2-one (2).

\section{Synthesis of Milnacipran Hydrochloride}

The synthesis of milnacipran hydrochloride synthesis starts with commercially available compound [25] 2. The treatment of compound 2 with aluminum chloride and diethylamine at room temperature afforded a ring opening alcohol 3 (Scheme 5). The alcohol compound 3 after workup directly proceeded to oxidation with Dess-Martin periodinane [DMP; 1,1,1-tris(acetyloxy)-1,1-dihydro-1,2-benziodoxol-3-(1$\mathrm{H})$-one]; this reagent has several advantages over chromium and DMSO-based oxidation reagents that include milder conditions such as lower temperature, neutral $\mathrm{pH}$, shorter reaction times, higher yields, simplified workups, high chemoselectivity, tolerance of sensitive functional groups, and a longer shelf life time. Oxidation with Swern reagent is tedious and hazardous; the by-products are dimethyl sulfide $\left(\mathrm{Me}_{2} \mathrm{~S}\right)$, carbon monoxide (CO), and carbon dioxide $\left(\mathrm{CO}_{2}\right)$. Two of the by-products, dimethyl sulfide and carbon monoxide, are very toxic volatile compounds; due to low boiling point dimethyl sulfide easily evaporates into atmosphere; this contributes to the already abundant pollution in the atmosphere. To overcome these challenges, Swern oxidation was replaced with the DMP reagent. From scale up point of view, DMP oxidation is much easier 


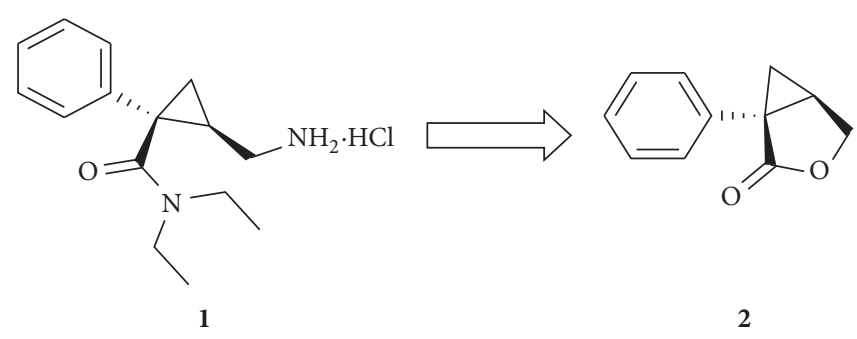

SCHEME 4: Retrosynthesis of milnacipran.

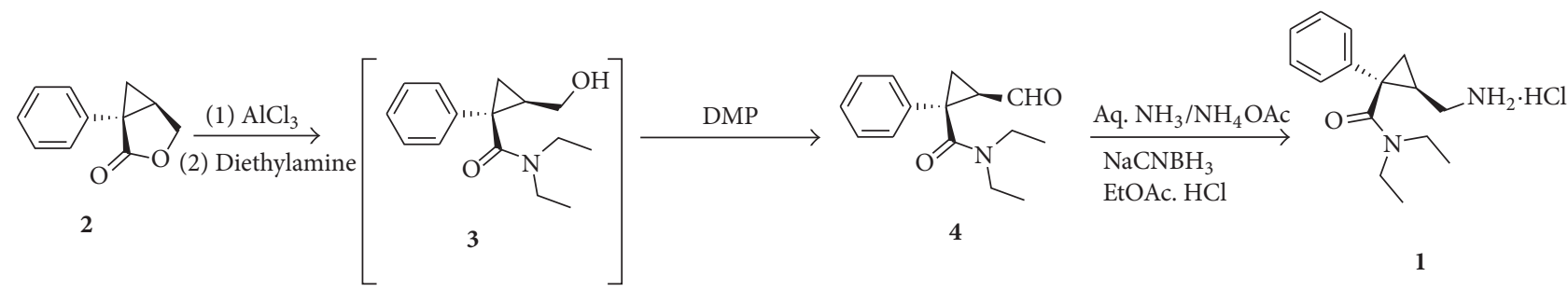

SCHEMe 5

TABLE 1: Solvent volume optimization.

\begin{tabular}{lccc}
\hline Entry & Reagent & DCM $(\mathrm{mL})$ & Yield (\%) \\
\hline 1 & DMP & 5 & 40 \\
2 & DMP & 10 & 60 \\
3 & DMP & 15 & 70 \\
4 & DMP & 20 & 95 \\
\hline
\end{tabular}

TABLE 2: Reagent mole equivalent optimization table.

\begin{tabular}{lccc}
\hline Entry & DMP $^{\text {b }}$ & Solvent & Yield\% \\
\hline 1 & 0.8 & DCM & 50 \\
2 & 0.9 & DCM & 70 \\
3 & 1.0 & DCM & 83 \\
4 & 1.1 & MDC & 95 \\
\hline
\end{tabular}

b: Dess-Martin periodinane reagent.

than Swern oxidation. Several parameters were selected to optimize the oxidation reaction, including solvent volumes and mole equivalents of reagent.

Oxidation of compounds 3 to $\mathbf{4}$ solvent volumes mentioned at Table 1, entries 1, 2, and 3 indicates that less volume of dichloromethane (DCM) is not favoured for this reaction. As per entry 4 higher volumes (20 volumes) are optimum for the DMP oxidation.

DMP reagent optimization mentioned in Table 2, entries 1 and 2 , shows poor yields due to incomplete reaction, whereas entry 3 is the optimum amount of reagent to get best results. Entry 4 also indicates that $1.1 \mathrm{eq}$ of DMP reagent is the suitable quantity to complete the reaction. Compound 3 was confirmed by ${ }^{1} \mathrm{H}$-NMR, significant peak observed at $9.05 \delta$ ppm for aldehyde.

Reductive amination step depends on the various factors like number of moles of reagent, $\mathrm{pH}$, reaction time, and temperature. Reductive amination was tried at different $\mathrm{pH}$ conditions as indicated in Table 3 and reaction optimization studied by adding additives like acetic acid and aq. ammonia solution. As mentioned in the table entry 1 was performed by adding acetic acid to the reaction, multiple number of spots was observed in the TLC, based on the theory, the probable side products were mentioned in the Scheme 6, and next entries 2 and 3 indicate incremental usage of ammonia gradually shifting towards chemoselctivity of reductive amination. Entry 4 clearly represents the higher volumes of ammonia or maintaining $\mathrm{pH} 12$ is the key factor to increase the chemoselective reductive amination of aldehyde 4 .

Second factor is the reaction temperature. Reaction was not proceeded at RT (entry 1, Table 4) to give desired primary amine 1 . TLC showed reaction stopped at imine step only. Entry numbers 2 and 3 indicate that gradual increase in temperature enhances the conversion of compound 1 . $70-75^{\circ} \mathrm{C}$ range is the optimum temperature for reductive amination of aldehyde 3 .

Metal hydride plays the main role in the reduction during reductive amination; to understand the impact of mole equivalent of $\mathrm{NaCNBH}_{3}$ some optimization results were mentioned in Table 5. Entry number 1 indicates that 0.5 eq of reagent is not good enough to complete reaction; same way entry numbers 2 and 3 also indicate that this reaction requires more eq of reagent $\left(\mathrm{NaCNBH}_{3}\right)$. Entry 4 clearly indicates that reductive amination of aldehyde and ammonia requires $3 \mathrm{eq}$ of reagent to get maximum conversion of compound 1 .

Reaction time is also the important factor to achieve desired product with highest yield; entry number 1 indicates $1 \mathrm{hr}$ is not enough to complete this reaction; as per Table 6 (entries 2 and 3) 2-4 hrs is also not sufficient for reductive amination reaction. Reaction time 6 hrs (entry 4, Table 6) was optimum reaction time to get maximum yield of compound 1.

Finally the optimized conditions for the synthesis of compound $\mathbf{1}$ from aldehyde 3 were 40 eq of aq. ammonia, 3 eq of sodium cyanoborohydride, 20 volumes of ethanol, and 
<smiles>CCN(CC)C(=O)[C@]1(c2ccccc2)C[C@H]1C=O</smiles>

4

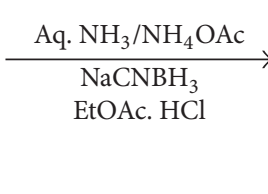

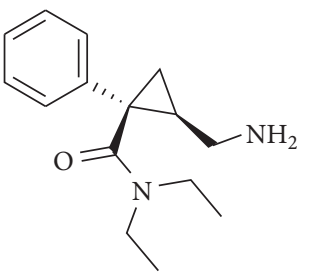

1<smiles>CCN(CC)C(=O)[C@@]1(c2ccccc2)C[C@H]1CNC[C@@H]1C[C@]1(C(=O)N(CC)CC)c1ccccc1</smiles>

5<smiles>CCN(CC)C(=O)C1(C(=O)N(CC)CC)C[C@H]1CN(C[C@@H]1CC1(c1ccccc1)c1ccccc1)C[C@@H]1C[C@@]1(C(=O)N(CC)CC)c1ccccc1</smiles>

6

Scheme 6: Overreductive amination.

TABLE 3: $\mathrm{pH}$ of the reaction mixture.

\begin{tabular}{|c|c|c|c|c|}
\hline Entry & Additive & $\mathrm{pH}$ & Ratio $^{\mathrm{a}}(\mathbf{1}: 5)$ & Yield \% \\
\hline 1 & $\mathrm{AcOH}$ & 7 & $1: 1$ & 40 \\
\hline 2 & Aq. $\mathrm{NH}_{3}(5 \mathrm{eq})$ & 8 & $4: 1$ & 50 \\
\hline 3 & Aq. $\mathrm{NH}_{3}(10 \mathrm{eq})$ & 10 & $10: 1$ & 65 \\
\hline 4 & Aq. $\mathrm{NH}_{3}(40 \mathrm{eq})$ & 12 & $20: 1$ & 75 \\
\hline
\end{tabular}

a: ratios calculated based on TLC profile.

TABLE 4: Reductive amination reaction temperature.

\begin{tabular}{lccc}
\hline Entry & Ethanol $\mathrm{mL}$ & Temp $^{\circ} \mathrm{C}$ & Yield\% \\
\hline 1 & 20 & RT & No rxn \\
2 & 20 & 40 & 25 \\
3 & 20 & 55 & 57 \\
4 & 20 & 75 & 75 \\
\hline
\end{tabular}

TABLE 5: $\mathrm{NaCNBH}_{3}$ mole eq optimization.

\begin{tabular}{lcrc}
\hline Entry & $\mathrm{NaCNBH}_{3}$ eq & Temp ${ }^{\circ} \mathrm{C}$ & Yield\% \\
\hline 1 & 0.5 & 75 & 28 \\
2 & 1 & 75 & 45 \\
3 & 2 & 75 & 55 \\
4 & 3 & 75 & 75 \\
\hline
\end{tabular}

TABLE 6: Reaction time optimization.

\begin{tabular}{lcrcc}
\hline Entry & Reagent & Temp ${ }^{\circ} \mathrm{C}$ & Rxn time (h) & Yield\% \\
\hline 1 & $\mathrm{NaCNBH}_{3}$ & 75 & 1 & 28 \\
2 & $\mathrm{NaCNBH}_{3}$ & 75 & 2 & 45 \\
3 & $\mathrm{NaCNBH}_{3}$ & 75 & 4 & 55 \\
4 & $\mathrm{NaCNBH}_{3}$ & 75 & 6 & 75 \\
\hline
\end{tabular}

6-7 hrs reaction time with saturated solution of ammonium acetate. Based on optimized conditions, we attempted gram scale synthesis of milnacipran hydrochloride (1). Characterization of 2-(aminomethyl)-N,N-diethyl-1-phenyl cyclopropane carboxamide hydrochloride (1) was done by proton ${ }^{1} \mathrm{HNMR},{ }^{13} \mathrm{C} \mathrm{NMR}$, and mass; significant broad amine peak is observed at $8.82 \delta \mathrm{ppm}$ and disappearance of peak at 9.05 ppm, which is related to corresponding aldehyde peak. $\mathrm{m} / \mathrm{z}$ peak is observed at 247.2 which is $\mathrm{M}+1$ of milnacipran hydrochloride $\mathbf{1}$.

\section{Conclusion}

We have demonstrated the synthesis of milnacipran hydrochloride with an efficient approach. We employed different conditions to obtain adequate experimental conditions such as $\mathrm{pH}$, temperature, and sodium cyanoborohydride reagent. In addition, the employment of reductive amination of aldehyde with sodium cyanoborohydride selectively produces primary amine with high yielding. Finally, we have developed a mild method for the conversion of the aldehyde into primary amine using reductive amination method.

\section{Experimental Section}

5.1. Synthesis of (1S,2R)-1-Phenyl-2-(hydroxymethyl)-N,N-diethyl Cyclopropane Carboxamide (3). Aluminum chloride (22 g) was suspended in $(150 \mathrm{~mL}) \mathrm{CH}_{2} \mathrm{Cl}_{2}$ and diethylamine 
( $25 \mathrm{~g}$ ) was then added under stirring at room temperature, slowly cooled to $0-5^{\circ} \mathrm{C}$, and stirred for 10 minutes, and the $\mathrm{RM}$ temperature was raised to $10-15^{\circ} \mathrm{C} ; 20 \mathrm{gm}$ of cis $( \pm)$ 1-phenyl-3-oxabicyclo[3.1.0]hexane-2-one was dissolved in $\mathrm{CH}_{2} \mathrm{Cl}_{2}(50 \mathrm{~mL})$ and added to the reaction mass for 1 hour at $10-15^{\circ} \mathrm{C}$. The temperature of the reaction mass was raised at room temperature and stirred for 1 hour. After completion of the reaction, the reaction mass was quenched in ice-cooled water $(140 \mathrm{~mL})$. The organic layer was collected and washed with water and hydrochloric acid. Aqueous layer was back extracted with $\mathrm{CH}_{2} \mathrm{Cl}_{2}(2 \times 100 \mathrm{~mL})$; combined organic layer was directly taken as such for the next step.

\subsection{Synthesis of (1S,2R)-1-Phenyl-2-formyl-N,N-diethyl Cyclo-} propane Carboxamide (4). To a solution of 3 (1 eq) in $\mathrm{CH}_{2} \mathrm{Cl}_{2}$ $(400 \mathrm{~mL})$ was added Dess-Martin periodinane (1.1 eq) at RT and the resulting solution was stirred for 2 hours at RT. The reaction mixture was quenched with a saturated solution of $\mathrm{Na}_{2} \mathrm{SO}_{3}$ and $\mathrm{NaHCO}_{3}$; the reaction mixture was passed through a pad of celite. The combined organic phase was dried over anhydrous $\mathrm{Na}_{2} \mathrm{SO}_{4}$, concentrated, and purified by column chromatography (silica gel : AcOEt/hexane, 1:2) to give 4 as a white solid (95\%). ${ }^{1} \mathrm{H}-\mathrm{NMR}$ : $\left(400 \mathrm{MHz}, \mathrm{CDCl}_{3}\right.$ ) $\delta: 0.69(3 \mathrm{H}, \mathrm{t}, J=7.0 \mathrm{~Hz}), 1.11(3 \mathrm{H}, \mathrm{t}, J) 7.0 \mathrm{~Hz}), 1.71(1 \mathrm{H}, \mathrm{dd}$, J) $5.5,8.5 \mathrm{~Hz}), 2.28(1 \mathrm{H}, \mathrm{dd}, J=5.5,6.0 \mathrm{~Hz}), 2.50(1 \mathrm{H}, \mathrm{ddd}$, $J=6.0,6.0,8.5 \mathrm{~Hz}), 3.18(1 \mathrm{H}, \mathrm{dq}, J=14.0,7.0 \mathrm{~Hz}), 3.26(1 \mathrm{H}$, $\mathrm{dq}, J=14.0,7.0 \mathrm{~Hz}), 3.42(1 \mathrm{H}, \mathrm{dq}, J=14.0,7.0 \mathrm{~Hz}), 3.46(1 \mathrm{H}$, $\mathrm{dq}, J) 14.0,7.0 \mathrm{~Hz}), 7.23-7.38(5 \mathrm{H}, \mathrm{m}), 9.05(1 \mathrm{H}, \mathrm{d}, J=6.0 \mathrm{~Hz})$. LC-MS $246.26(\mathrm{M}+1)$ peak found with purity $98 \%$.

\subsection{Synthesis of 2-(Aminomethyl)-N,N-diethyl-1-phenyl Cyclo-} propane Carboxamide Hydrochloride (1). To a solution of 4 $(1.0 \mathrm{eq})$ in a saturated solution of $\mathrm{NH}_{4} \mathrm{OAc}$ in ethanol $(20 \mathrm{~mL})$ were added $\mathrm{NaCNBH}_{3}$ (3 eq) and $30 \%$ aqueous ammonia $(8 \mathrm{~mL})$. The mixture was stirred at reflux for $6 \mathrm{hrs}$, cooled to $\mathrm{RT}$, and concentrated under reduced pressure to get crude product. Ethyl acetate hydrochloride was added to the crude product; corresponding hydrochloride salt was isolated and filtered under vacuum to get 1 as a crystal $(23 \mathrm{~g}, 70 \%)$. Mp 178-180 ${ }^{\circ}$ C. ${ }^{1} \mathrm{H}$ NMR: $\left(\mathrm{CDCl}_{3}, 400 \mathrm{MHz}\right) \delta: 0.90(\mathrm{t}, 3 \mathrm{H}, J=$ $7.2 \mathrm{~Hz}), 1.11(\mathrm{t}, 3 \mathrm{H}, J=7.2 \mathrm{~Hz}), 1.76-1.83(\mathrm{~m}, 2 \mathrm{H}), 2.45(\mathrm{~m}$, $1 \mathrm{H}), 3.35-3.40(\mathrm{~m}, 4 \mathrm{H}), 3.73-3.76(\mathrm{~m}, 1 \mathrm{H}), 7.10-7.29$ (m, Ar, $5 \mathrm{H}), 8.82$ (br, s, $2 \mathrm{H}) ;{ }^{13} \mathrm{C} \mathrm{NMR}:\left(\mathrm{CDCl}_{3}, 100 \mathrm{MHz}\right) \delta: 11.9(1 \mathrm{C}$, $\mathrm{CH} 3), 12.6$ (1C, CH3), 17.8 (1C, CH2), 24.9 (1C, CH), 39.2 (1C, $\mathrm{N}-\mathrm{CH} 2), 41.66$ (1C, N-CH2), 42.4 (1C, N-CH2), 125.4 (Ar, 2C), 126.7 (Ar, 1C), 128.5 (Ar, 2C), 138.1 (Ar, 1C), 170.1 (1C, amide); $m / z: 247.2(\mathrm{M}+1)$.

\section{Conflicts of Interest}

The authors declare that there are no conflicts of interest.

\section{Acknowledgments}

The authors are grateful to the Management of Nifty Labs Pvt. Limited, Hyderabad, for supporting this work and cooperation from other colleagues also is highly appreciated.

\section{References}

[1] J. Deregnaucourt and R. Grosse, WO Patent, 2004075886, 2003.

[2] L. Mansuy, WO Patent, 2009127737, 2008.

[3] G. Mouzin, H. Cousse, and B. Bonnaud, "A convenient synthesis of bifunctional vicinal cyclopropanes," Synthesis, vol. 4, pp. 304305, 1978.

[4] S. Shuto, H. Takada, D. Mochizuki et al., “( \pm )-(Z)-2-(aminomethyl)-1-phenylcyclopropanecarboxamide derivatives as a new prototype of NMDA receptor antagonists," Journal of Medicinal Chemistry, vol. 38, no. 15, pp. 2964-2968, 1995.

[5] M. Zhang and P. E. Eaton, "BuMgNiPr 2 : a new base for stoichiometric, position-selective deprotonation of cyclopropane carboxamides and other weak $\mathrm{CH}$ acids," Angewandte Chemie International Edition, vol. 41, no. 12, pp. 2169-2171, 2002.

[6] K. Vervisch, M. D. Hooghe, K. W. Tornoos, and N. De Kimpe, "A new approach towards 1-phenyl and 1-benzyl substituted 2(aminomethyl)cyclopropanecarboxamides as novel derivatives of the antidepressant Milnacipran," Organic \& Biomolecular Chemistry, vol. 7, pp. 3271-3279, 2009.

[7] F. Kagan, M. A. Rebenstorf, and R. V. Heinzelman, "The preparation of glycamines," Journal of the American Chemical Society, vol. 79, no. 13, pp. 3541-3544, 1957.

[8] A. Lauritsen and R. Madsen, "Synthesis of naturally occurring iminosugars from d-fructose by the use of a zinc-mediated fragmentation reaction," Organic and Biomolecular Chemistry, vol. 4, no. 15, pp. 2898-2905, 2006.

[9] S. K. Sharma, M. F. Songster, T. L. Colpitts, P. Hegyes, G. Barany, and F. J. Castellino, "Reductive amination with tritylamine as an ammonia equivalent: efficient preparation of the 5-[4-[[(9fluorenylmethyloxycarbonyl)-amino]methyl]-3,5-dimethoxyphenoxy]valeric acid (PAL) handle for peptide synthesis," Journal of Organic Chemistry, vol. 58, no. 18, pp. 4993-4995, 1993.

[10] H. Katayama, T. Utsumi, C. Ozawa, Y. Nakahara, H. Hojo, and Y. Nakahara, "Pyruvoyl, a novel amino protecting group on the solid phase peptide synthesis and the peptide condensation reaction," Tetrahedron Letters, vol. 50, no. 7, pp. 818-821, 2009.

[11] M. Kojima, Y. Nakamura, A. Nakamura, and S. Takeuchi, “Total synthesis of cucurbitoside A using a novel fluorous protecting group," Tetrahedron Letters, vol. 50, no. 8, pp. 939-942, 2009.

[12] A. Ali, R. J. B. H. N. van den Berg, H. S. Overkleeft, D. V. Filippov, G. A. van der Marel, and J. D. C. Codée, "Methylsulfonylethoxycarbonyl (Msc) and fluorous propylsulfonylethoxycarbonyl (FPsc) as hydroxy-protecting groups in carbohydrate chemistry," Tetrahedron Letters, vol. 50, no. 19, pp. 2185-2188, 2009.

[13] M. S. M. Timmer, B. L. Stocker, P. T. Northcote, and B. A. Burkett, "Az-a colourful azulene-derived protecting group," Tetrahedron Letters, vol. 50, no. 51, pp. 7199-7204, 2009.

[14] B. M. Trost, "The atom economy-a search for synthetic efficiency," Science, vol. 254, no. 5037, pp. 1471-1477, 1991.

[15] R. F. Borch, M. D. Bernstein, and H. D. Durst, "Cyanohydridoborate anion as a selective reducing agent," Journal of the American Chemical Society, vol. 93, no. 12, pp. 2897-2904, 1971.

[16] P. Bowles, J. Clayden, M. Helliwell, C. McCarthy, M. Tomkinson, and N. Westlund, "Atroposelectivity in the reactions of ortholithiated aromatic tertiary amides with aldehydes," Journal of the Chemical Society-Perkin Transactions 1, no. 17, pp. 26072616, 1997. 
[17] A. Pelter, R. M. Rosser, and S. Mills, "Reductive aminations of ketones and aldehydes using borane-pyridine," Journal of the Chemical Society, Perkin Transactions 1, pp. 717-720, 1984.

[18] B. Bonnaud, G. Mouzin, H. Cousse, and J. F. Patoiseau, European Patent Publication 0200638, 1986.

[19] M. Nicolas, P. Hellier, C. Diard, and L. Subra, European Patent Publication 2391599, 2010.

[20] J. Alliot, E. Gravel, F. Pillon, D.-A. Buisson, M. Nicolas, and E. Doris, "Enantioselective synthesis of levomilnacipran," Chemical Communications, vol. 48, no. 65, pp. 8111-8113, 2012.

[21] E. M. Dangerfield, C. H. Plunkett, A. L. Win-Mason, B. L. Stocker, and M. S. M. Timmer, "Protecting-group-free synthesis of amines: synthesis of primary amines from aldehydes via reductive amination," Journal of Organic Chemistry, vol. 75, no. 16, pp. 5470-5477, 2010.

[22] S. Shuto, S. Ono, Y. Hase, N. Kamiyama, and A. Matsuda, "Synthesis of (+)- and (-)-milnaciprans and their conformationally restricted analogs," Tetrahedron Letters, vol. 37, no. 5, pp. 641644, 1996.

[23] S. Shuto, S. Ono, H. Imoto, K. Yoshii, and A. Matsuda, "Synthesis and biological activity of conformationally restricted analogues of milnacipran: (1S,2R)-1-phenyl-2-[(R)-1-amino-2propynyl]-N,N- diethylcyclopropanecarboxamide is a novel class of NMDA receptor channel blocker," Journal of Medicinal Chemistry, vol. 41, no. 18, pp. 3507-3514, 1998.

[24] P. R. Gopal, A. C. Prabakar, E. R. R. Chandrashekar, B. V. Bhaskard, and P. V. Somaiah, "Synthesis and characterization of process related impurities of ( \pm )-Milnacipran," Journal of the Chinese Chemical Society, vol. 60, no. 6, pp. 639-644, 2013.

[25] S. Shuto, S. Ono, Y. Hase et al., "Conformational restriction by repulsion between adjacent substituents on a cyclopropane ring: design and enantioselective synthesis of 1-phenyl-2-(1-aminoalkyl)- $N, N$-diethylcyclopropanecarboxamides as potent NMDA receptor antagonists," Journal of Organic Chemistry, vol. 61, no. 3, pp. 915-923, 1996. 

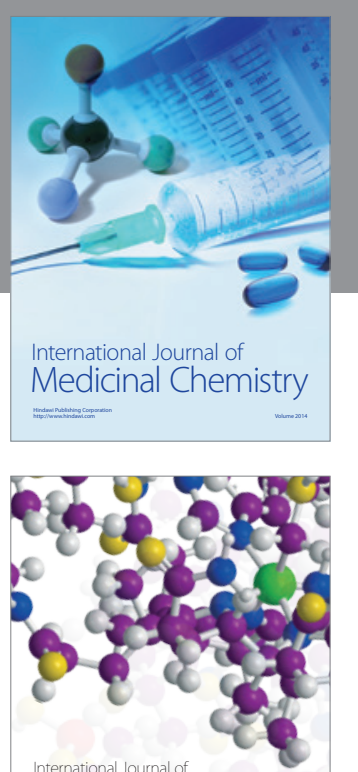

Carbohydrate Chemistry

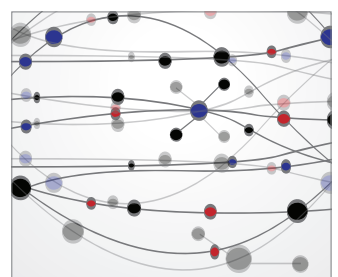

The Scientific World Journal
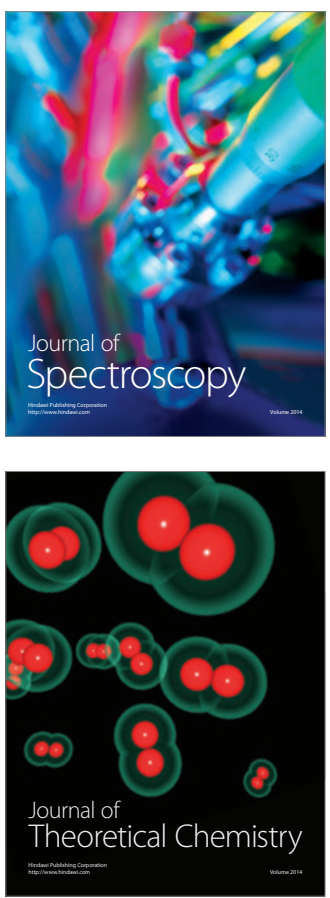
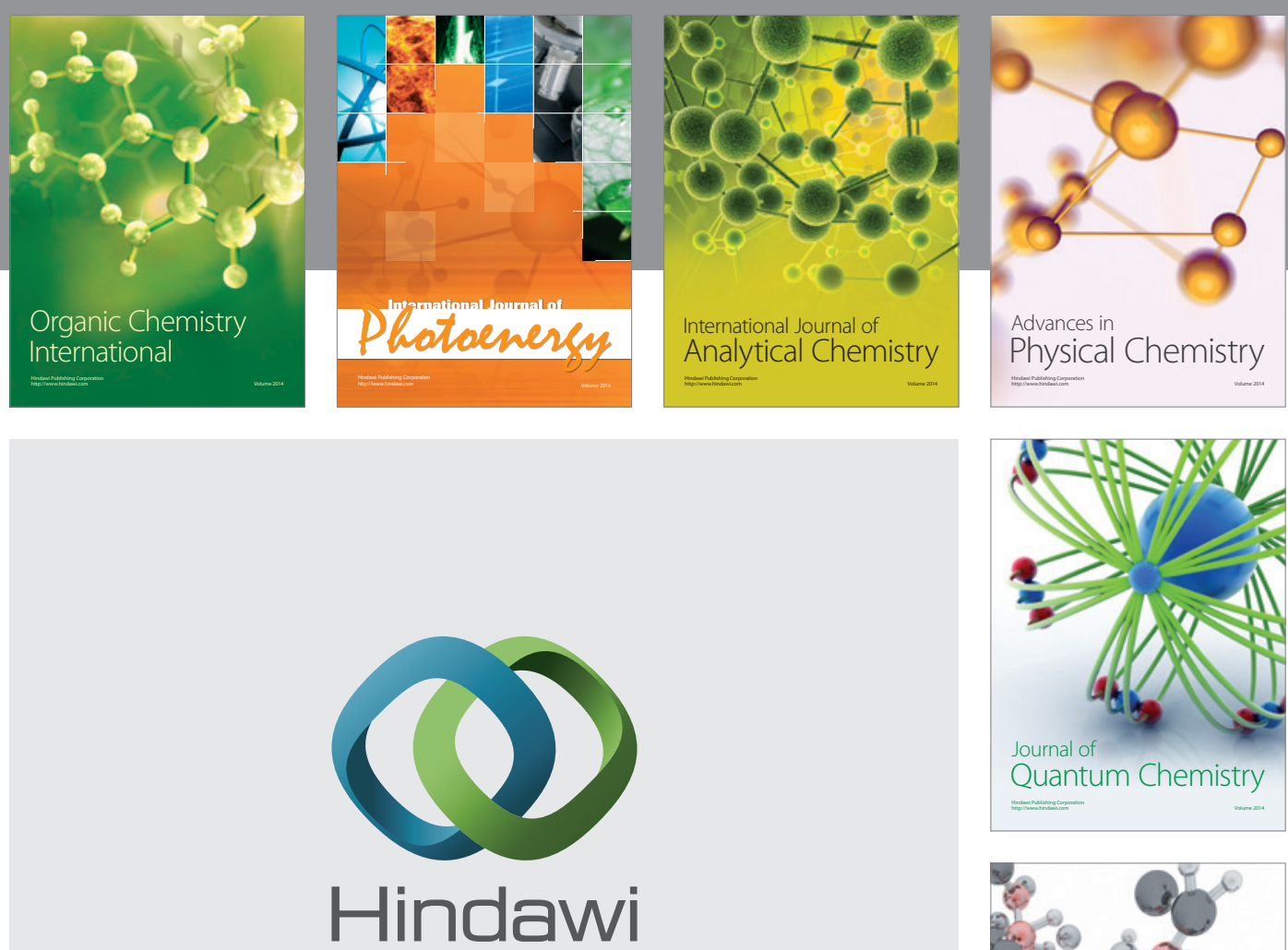

Submit your manuscripts at

https://www.hindawi.com

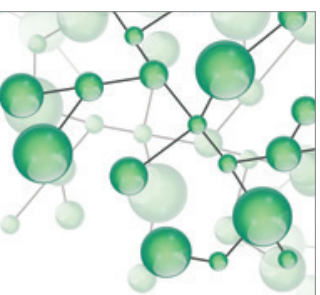

International Journal of

Inorganic Chemistry
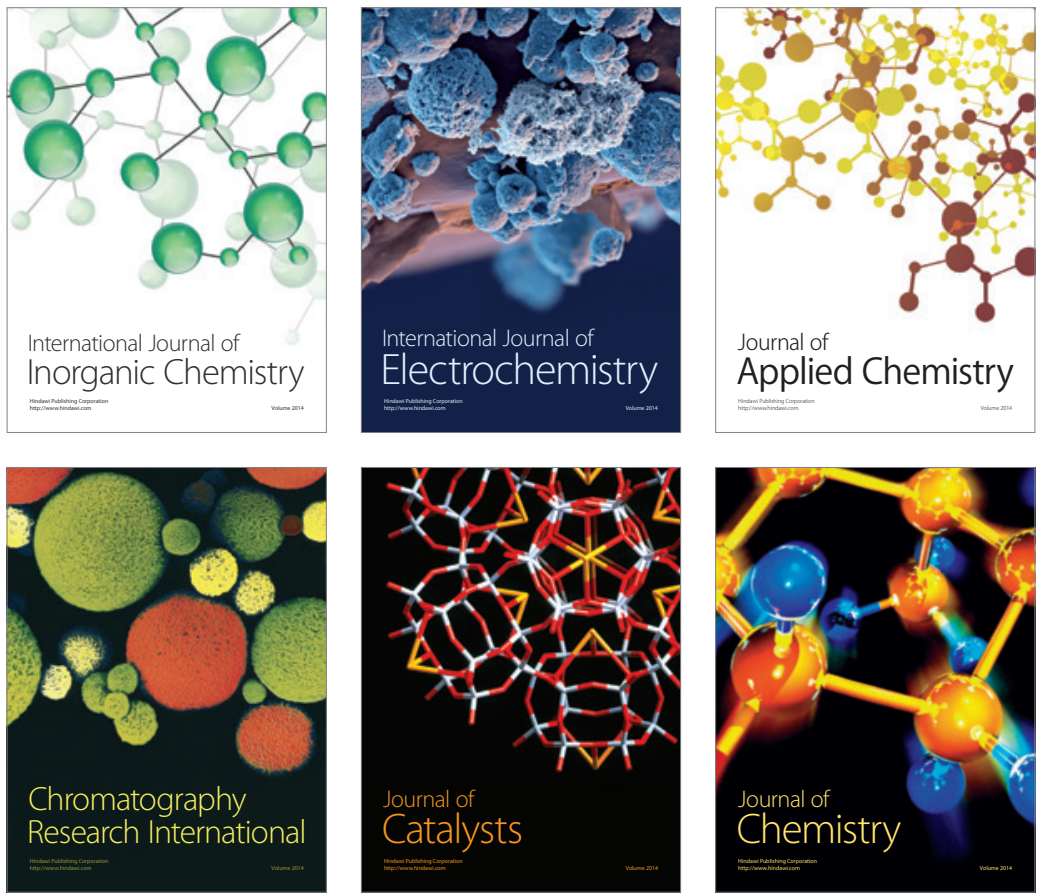

Journal of

Applied Chemistry
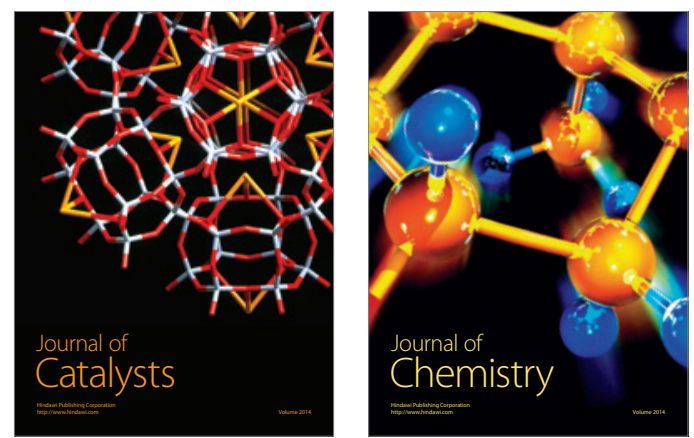
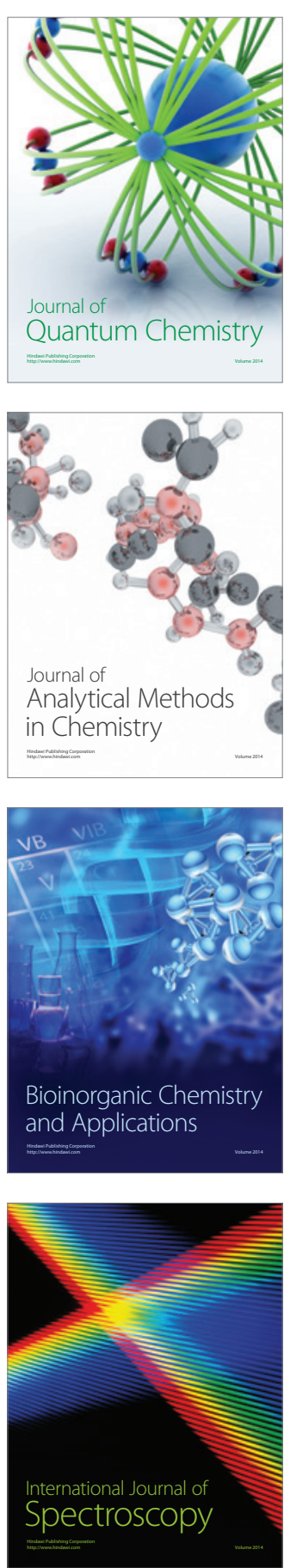